\title{
Media Pembelajaran Bulutangkis dalam Bentuk Multimedia Interaktif pada Mahasiswa
}

\author{
Frendy Anang Pratama ${ }^{1}$, Wasis Djoko Dwiyogo ${ }^{1}$, Supriyadi ${ }^{1}$ \\ ${ }^{1}$ Pendidikan Olahraga-Universitas Negeri Malang
}

\begin{tabular}{l}
\hline \hline INFO ARTIKEL \\
\hline Riwayat Artikel: \\
Diterima: $13-12-2018$ \\
Disetujui: $18-03-2019$ \\
\hline
\end{tabular}

\section{Kata kunci:}

instructional media; interactive multimedia; badminton;

media pembelajaran; multimedia interaktif; bulutangkis

Alamat Korespondensi:
Frendy Anang Pratama
Pendidikan Olahraga
Universitas Negeri Malang
Jalan Semarang 5 Malang
E-mail: frendypratama27@gmail.com

\section{ABSTRAK}

Abstract: This research was aimed to develop teaching materials for badminton material in the form of interactive multimedia. The results of the badminton expert validation showed a percentage of $91.89 \%$, learning experts showed a percentage of $89.58 \%$ and the results of media expert validation showed a percentage of $87.80 \%$. With the results of the validation, the product is feasible to be tested. Furthermore, for product trials, the percentage of small group trials was $90.10 \%$ and the percentage of large group trials was $91.15 \%$.

\begin{abstract}
Abstrak: Penelitian ini bertujuan untuk mengembangkan bahan pembelajaran untuk materi bulutangkis ke dalam bentuk multimedia interaktif. Hasil validasi ahli bulutangkis menunjukkan persentase sebesar $91,89 \%$, ahli pembelajaran menunjukkan persentase sebesar $89,58 \%$ dan hasil validasi ahli media menunjukkan persentase sebesar $87,80 \%$. Dengan hasil validasi tersebut maka produk layak untuk diujicobakan. Selanjutnya, untuk uji coba produk, persentase ujicoba kelompok kecil sebesar 90,10\% dan persentase ujicoba kelompok besar sebesar $91,15 \%$.
\end{abstract}

Di era yang semakin maju ini, pemanfaatan teknologi dan komunikasi masuk ke dalam semua sektor kehidupan, termasuk dalam sektor pendidikan. Semakin pesatnya perkembangan teknologi informatika dalam bidang pendidikan sehingga memberikan banyak pengaruh pada proses pembelajarannya. (Stepp, 2002) berpendapat bahwa dalam proses pembelajaran, adanya perubahan (a) bergeraknya pendidikan dari pusat guru ke pusat siswa dan (b) pendidikan terbuka atau dapat dilaksanakan melalui jarak jauh. (Riyana, 2010) menyatakan bahwa salah satu kecenderungan pada proses pembelajaran yaitu semakin banyaknya pilihan sumber belajar yang tersedia. (Nazarenko, 2014) perkembangan teknologi dapat membantu mengembangkan strategi dan model pengajaran yang efektif sehingga pembelajaran lebih menarik sesuai tuntutan teknologi. Multimedia merupakan salah satu bentuk sumber belajar dari komputer. (Munadi, 2010) menyebutkan bahwa multimedia merupakan proses pembelajaran yang melibatkan semua indera yang dimiliki manusia dalam proses pembelajaran itu sendri. Jika pengguna memperoleh kebebasan dalam menggunakan multimedia tersebut, bahwa ini dapat dikatakan proses pembelajaran multimedia interaktif (Wijaya, 2010). Menurut (Dwiyogo, 2008) menyatakan bahwa pembelajaran yang didesain dalam konsep pembelajaran multimedia interaktif dapat dibedakan menjadi empat model, yaitu drills, tutorial, simulasi, dan games (instructional games). Masing-masing model memiliki karakteristik yang berbeda, baik dari sudut desain, isi, tujuan, keleluasaaan-kedalaman, serta kualitas pemanfaatan dan pengembangan komputernya itu sendiri. Multimedia interaktif didesain agar pembelajar dapat belajar secara mandiri, aktif, cerdas, dan terkendali (Dwiyogo, 2009).

Kemandirian dari peserta didik sangat dibutuhkan di era pendidikan yang semakin modern ini. Siswa dituntut untuk memiliki sifat kemandirian dalam proses pembelajaran, hal ini dikarenakan untuk menunjang prestasi (Pintrich \& Groot, 1990). Kemandirian belajar merupakan proses proaktif sebagai konteks perubahan belajar siswa dan perkembangan siswa (Barnard, Lan, To, Paton, \& Lai, 2009). Kemandirian belajar dibutuhkan dalam menunjang proses pembelajaran online pada blended learning sehingga siswa dapat belajar secara aktif (Zitting \& Kraue, 2005). Dengan proses pembelajaran yang masih konvensional, keberadaan multimedia interaktif dengan karakteristik yang bisa dipelajari dimanapun dan kapanpun akan sangat membantu kemandirian belajar peserta didik. Multimedia interaktif dapat menunjang proses pembelajaran matakuliah bulutangkis di Jurusan Pendidikan Jasmani dan Kesehatan Universitas Mulawarman.

Berdasarkan hasil observasi yang dilaksanakan pada saat proses pembelajaran bulutangkis diperoleh data sebagai berikut. Pertama, dosen hanya menggunakan buku sebagai media pembelajaran. Kedua, pembelajaran di dalam kelas hanya dua kali pertemuan, sisanya langsung praktik di lapangan. Ketiga, tidak semua mahasiswa mempunyai buku peraturan maupun teknik dasar bulutangkis. Keempat, mahasiswa kurang antusias dengan proses pembelajaran. Kelima, dosen hanya memberikan pokok-pokok materi bulutangkis, sedangkan yang lainnya dipahami mahasiswa sendiri. Berdasarkan penyebaran angket analisis 
kebutuhan untuk mahasiswa dan dosen diperoleh data sebagai berikut. Pertama, 78,12\% responden kurang memahami materi yang diberikan menggunakan buku. Kedua, 100\% dosen belum pernah menggunakan multimedia interaktif saat perkuliahan. Ketiga, 12,5\% menyukai e-book sebagai media pembelajaran, 25\% menyukai bentuk VCD Pembelajaran, 56,25\% menyukai bentuk pembelajaran multimedia interaktif, dan 6,25\% menyukai buku teks. Keempat, 100\% menginginkan untuk dikembangan media pembelajaran konvensional dalam bentuk multimedia interaktif.

\section{METODE}

Model penelitian yang digunakan mengacu pada model pengembangan (Lee \& Owens, 2004) dengan langkahlangkahnya (1) melakukan analisis kebutuhan, (2) mendesain, (3) pengembangan, (4) implementasi, dan (5) evaluasi. Langkah yang dikemukakan oleh Lee \& Owens tersebut adalah langkah-langkah dalam memecahkan suatu permasalahan penelitian yang nantinya dalam pemecahan masalah tersebut menghasilkan sebuah produk. Hal ini, peneliti ingin mengembangkan sebuah produk multimedia interaktif. Tentunya, dalam membuat suatu produk penelitian sebelum diterjunkan dilapangan, agar produk tersebut layak untuk digunakan harus divalidasi dan dievaluasi oleh ahli yang kompeten di bidangnya. Setelah tervalidasi, produk pengembangan bisa diujikan dalam skala kelompok kecil atau besar untuk mengetahui kekurangan dan kelebihan produk yang dihasilkan.

Menggunakan angket untuk menjaring data dari subjek ahli di antaranya ahli bidang bulutangkis, ahli media pembelajaran, dan data dari subjek coba. Bentuk angket tiap ahli berbeda. Selain itu, ada penyebaran angket untuk mahasiswa sebagai bentuk uji coba 1 dan 2 untuk penilaian dan tanggapan mahasiswa jurusan Pendidikan Jasmani dan Keolahragaan Universitas Mulawarman Samarinda angkatan 2016 tentang produk yang dikembangkan.

Data yang untuk digunakan dalam penelitian dan pengembangan ini merupakan data kualitatif dan kuantitatif. Data kualitatif digunakan sebagai tinjauan ahli, berupa saran dan masukan terhadap produk yang dikembangkan, sedangkan data kuantitatif digunakan untuk menghitung data uji coba 1 dan 2. Teknis analisis ini menggunakan teknik analisis data analisis kualitatif dan deskriptif persentase. Dalam hal ini yang digunakan teknik analisis deskriptif dan analisis kualitatif yang mana analisis kualitatif digunakan untuk menganalisis data dari para ahli berupa masukan, komentar, kritik, dan saran. Hasil analisis data menjadi dasar dalam penyempurnaan pengembangan produk. Menurut (Sugiyono, 2011) langkah-langkah analisis data kualitatif, meliputi (1) reduksi data, (2) penyajian data, dan (3) verifikasi.

Dari setiap langkah diatas maka terakhir yaitu langkah verifikasi yang bermaksud untuk menarik kesimpulan. Kesimpulan awal yang telah didapat bersifat sementara dan berubah jika tidak ada ditemukan bukti-bukti, namun sebaliknya jika didukung oleh bukti-bukti yang cukup valid maka kesimpulan tersebut kredibel. Teknik analisis deskriptif persentase untuk menganalisis data yang didapat dari hasil penyebaran angket dalam dua kali uji coba. Rumus persentase sebagai berikut:

Keterangan

$$
V=\frac{T S E V}{S-\max } \times 100 \%
$$

$\begin{array}{ll}\mathrm{V} & : \text { Validitas } \\ \sum \mathrm{x} & \text { : Total Skor Empirik Validator } \\ \sum \mathrm{xi} & \text { : Skor maksimal yang diharapkan } \\ 100 \% & : \text { Konstanta }\end{array}$

Kelayakan produk pengembangan, maka ditetapkan penggolongannya sebagaimana yang diungkapkan oleh (Akbar \& Sriwiyana, 2010) yang ada pada tabel 1.

Tabel 1. Tabel Persentase Kriteria Kelayakan Produk Penelitian dan Pengembangan

\begin{tabular}{ll}
\hline Kriteria Pencapaian & Tingkat Validitas \\
\hline $75,01-100 \%$ & Sangat valid (Dapat digunakan tanpa revisi) \\
$50,01-75,00 \%$ & Cukup valid (Dapat digunakan dengan revisi kecil) \\
$25,01-50,00 \%$ & Tidak valid (Tidak dapat digunakan) \\
$00,00-25,00 \%$ & Sangat tidak Valid (Terlarang digunakan) \\
\hline
\end{tabular}

HASIL

\section{Analisis Kebutuhan}

Data observasi awal diperoleh dari hasil pengamatan peneliti terhadap proses pembelajaran bulutangkis. Berdasarkan pengamatan tersebut ditemukan data sebagai berikut. Pertama, proses pembelajaran bulutangkis langsung praktik di lapangan. Kedua, sumber belajar hanya buku. Ketiga, mahasiswa tidak punya sumber belajar alternatif selain buku. Keempat, tidak semua mahasiswa mempunyai buku, sedangkan dari hasil wawancara dengan dosen pengampu matakuliah bulutangkis diperoleh hasil sebagai berikut. Pertama, proses pembelajaran bulutangkis hanya satu kali di dalam kelas, sisanya praktik langsung di lapangan. Kedua, dosen tidak pernah memberikan materi atau teori di kelas. Ketiga, dosen hanya memberi buku pegangan dan tidak 
pernah dibahas di kelas. Keempat, dosen belum pernah memanfaatkan media pembelajaran berbasis teknologi. Berdasarkan data di atas dapat disimpulkan bahwa perlunya dikembangkan media ajar bulutangkis ke dalam bentuk multimedia interaktif yang digunakan sebagai media pembelajaran mahasiswa PJKR Universitas Mulawarman Samarinda.

\section{Analisis Validasi Pembelajaran Pendidikan Jasmani Kesehatan}

Data dari validasi ahli pembelajaran Pendidikan Jasmani Kesehatan diperoleh pada Selasa 03 April 2018, diperoleh hasil (1) aspek kesesuaian materi dengan kompetensi diperoleh persentase sebesar 85,00\%, (2) aspek keakuratan materi sebesar $91,67 \%$, dan (3) aspek penyajian sebesar 93,75\%. Saran dan masukan dari ahli media (1) penjelasan pada menu sarana dan prasarana lebih diperjelas dan (2) volume produk bisa diatur keras dan tidaknya.

\section{Analisis Validasi Materi Bulutangkis}

Berdasarakan hasil validasi pada Senin 26 Maret 2018 diperoleh persentase (1) kesesuaian materi footwork diperoleh persentase sebesar 95,83, (2) kesesuaian materi grip diperoleh persentase sebesar 93,75, (3) kesesuaian materi pukulan diperoleh persentase sebesar 83,33\%, (4) kesesuaian materi sarana dan prasarana diperoleh persentase sebesar 100\%, (5) kesesuaian materi perwasitan diperoleh persentase sebesar $100 \%$, (6) kesesuaian materi strategi permainan diperoleh persentase sebesar 100\%, (7) kesesuaian materi latihan mental diperoleh persentase sebesar 100\%, (8) kesesuaian materi latihan fisik diperoleh persentase sebesar 90,00\%, (9) kesesuaian materi sejarah diperoleh persentase sebesar 100\%, dan (10) kesesuaian materi peraturan permainan didapat persentase sebesar 100\%. Saran serta masukan dari ahli bulutangkis, meliputi (1) perlu ditambah materi tentang sejarah dan peraturan permainan bulutangkis dan (2) gerakan smash lebih diperjelas.

\section{Analisis Validisi Media}

Data dari hasil validasi ahli media diperoleh pada pada Senin 02 April 2018. diperoleh hasil yaitu: (1) aspek tampilan pembuka diperoleh persentase sebesar 96,43\%, (2) aspek tampilan menu utama sebesar 94,4\%, (3) aspek tampilan submenu sebesar $82,14 \%$ dan (4) aspek kualitas video sebesar 81,25\%. Saran serta masukan dari ahli media yaitu: (1) pada pada tampilan pembuka diberi efek suara, (2) font pada tampilan menu utama diperbesar dan dipertebal, (3) pada menu Keluar, gambar centang dan gambar silang diperkecil, (4) kalimat penutup diperkecil, dan (5) shadow pada gambar centang diganti dengan warna hijau.

\section{Analisis Data Uji Kelompok Kecil}

Uji coba kelompok kecil hasil analisis data yang telah dilakukan didapat dari tiga aspek atau kategori yang divalidasi, yaitu (1) kemenarikan, (2) kemudahan, dan (3) kejelasan. Aspek kemenarikan diperoleh persentase sebesar 93,06\%, aspek kemenarikan diperoleh persentase sebesar 89,96\%, dan aspek kejelasan diperoleh persentase sebesar 90,63\%. Berdasarkan hasil analisis data uji coba kelompok kecil maka produk pengembangan media pembelajaran bulutangkis dalam bentuk multimedia interaktif ini dinyatakan sangat valid dapat dilanjutkan ke tahap uji coba kelompok besar.

\section{Analisis Data Uji Kelompok Besar}

Uji kelompok besra hasil analisis data yang telah dilakukan diperoleh dari tiga aspek yang akan divalidasi, yaitu (1) kemenarikan, (2) kemudahan, dan (3) kejelasan. Aspek kemenarikan diperoleh persentase sebesar 91,94\%, aspek kemenarikan diketahui dengan persentase sebesar 91,06\%, dan aspek kejelasan diperoleh persentase sebesar 90,42\% Berdasarkan hasil analisis data uji coba kelompok besar maka produk pengembangan media pembelajaran bulutangkis dalam bentuk multimedia interaktif ini dinyatakan sangat valid dan dapat dijadikan media pembelajaran.

\section{PEMBAHASAN}

Setalah dilakukan pengembangan dengan memperhatikan beberapa tahapan maka dihasilkan media pembelajaran bulutangkis yang dikemas dalam bentuk multimedia interaktif. Produk pengembangan di sini berisi 10 materi tentang bulutangkis yang dilengkapi dengan kuis sebagai tes kognitif. Penelitian serupa juga dilakukan oleh (Muzaki, 2017) yang mengembangkan multimedia teknik dasar bulutangkis untuk atlet usia 7-12 tahun serta penelitian yang dilakukan oleh (Wibowo, 2013) yang mengembangkan media pembelajaran teknik dasar bulutangkis. Hal serupa penelitian oleh (Klentien \& Wannasawade, 2016) yang mengembangkan multimedia di sekolah menengah.

Berdasarkan penelitian yang telah dilaksanakan maka produk ini memperoleh respon dengan persentase untuk kriteria kemenarikan sebesar 91,94\%, kemudahan sebesar 91,06\%, dan kejelasan sebesar 90,42\%. Semua kriteria telah memenuhi kelayakan produk sehingga produk pengembaangan media pembelajaran bulutangkis dalam bentuk multimedia interaktif dinyatakan sangat valid dan layak digunakan. Produk pengembangan produk multimedia interaktif ini terdiri dari 10 materi tentang bulutangkis, meliputi (1) footwork, (2) grip, (3) teknik pukulan, (4) sarana dan prasarana, (5) perwasitan, (6) strategi permainan, (7) latihan mental, dan (8) latihan fisik, (9) sejarah, dan (10) peraturan permainan. 
Kelebihan produk ini antara lain (1) materi dikemas dalam satu file dalam bentuk aplikasi atau .exe yang dapat dioperasikan secara langsung tanpa membuka program pada komputer, (2) materi berisikan tentang video, musik, suara, animasi, gambar sehingga lebih menarik mahasiswa untuk mempelajari, (3) media ini dapat digunakan sebagai media belajar mandiri, (4) media ini juga mudah dan menarik sehingga memiliki nilai hiburan, (5) multimedia ini dapat diputar menggunakan media komputer sehingga penggunaannya tidak terbatas oleh ruang dan waktu. Penelitian serupa juga disampaikan (Tasleden \& Koseoglu, 2008) bahan ajar memberikan kemudahan bagi mahasiswa untuk memperaktikan materi dalam pelajaran dan adanya bahan ajar juga sebagai fasilitas untuk mencapai target kurikulum. Dalam proses pembelajaran yang baik di antaranya adalah banyaknya pilihan sumber belajar (Riyana, 2010). Elemen-elemen kunci media yaitu untuk mengontrol penyampaianpenyampaian informasi, interaktifnya dapat meningkatkan proses pembelajaran melalui penciptaan lingkungan belajar yang terintegrasi, keterangan dapat dikombinasikan melalui cara ilustrasi contoh-contoh, penilaian daring, umpan balik dan penggunaannya dapat diberikan memulai kesempatan berlatih dan eksperimen (Cairncross \& Mannion, 2001). (Husamah, 2014) dalam dunia pembelajaran, pemanfaatan media berbasis teknologi informasi dan komunikasi juga memungkinkan pengajar merekayasa media pembelajaran agar tujuan pembelajaran bisa dicapai lebih mudah.

Kombinasi media dan strategi pembelajaran yang sesuai juga diyakini banyak pihak mampu meningkatkan gairah belajar mahasiswa yang pada akhirnya akan menciptakan pebelajaran yang lebih menarik. Hal serupa juga disampaikan oleh (Baharudin, 2012) menarik untuk menghubungkan multimedia yang sering dimanfaatkan pendidik dalam pembelajaran dengan pemilihan strategi yang sesuai. (Abdillah, 2010) juga menyampaikan di era teknologi dalam pembelajaran kini pun harus dimanfaatkan.

\section{SIMPULAN}

Dari tinjauan para beberapa ahli terdapat sejumlah saran dan revisi terhadap produk yang akan dikembangkan, yaitu, hasil evaluasi dari para ahli adalah sebagai berikut (1) perlu ditambah materi tentang sejarah dan peraturan permainan bulutangkis, (2) gerakan smash lebih diperjelas, (3) penjelasan pada menu sarana dan prasarana lebih diperjelas, (4) volume produk bisa diatur keras dan tidaknya, (5) pada tampilan pembuka diberi efek suara, (6) font pada tampilan menu utama diperbesar dan dipertebal, (7) pada menu keluar, gambar centang dan gambar silang diperkecil, (8) kalimat penutup diperkecil, (9) shadow pada gambar centang diganti dengan warna hijau. Sementara itu, hasil dari uji coba menunjukkan persentase hasil yang sangat valid sehingga pengembangan media pembelajaran bulutangkis dalam bentuk multimedia interaktif layak digunakan dalam proses pembelajaran bulutangkis di Universitas Mulawarman Samarinda.

Jika dirasa ada perkembangan-perkembangan baru terkait permainan bulutangkis, produk ini dapat direvisi menyesuaikan perkembangan yang ada sehingga pengembangan media pembelajaran bulutangkis dalam bentuk multimedia interaktif ini lebih menarik dan bermanfaat khususnya bagi penggunanya pengembangan produk lebih lanjut terhadap pengembangan pembelajaran matakuliah bulutangkis berbasis blended learning serta efektivitas terhadap hasil belajar. Subjek penelitian ini diharapkan cakupannya dapat lebih luas, tidak hanya di Jurusan Pendidikan Jasmani Kesehatan Universitas Mulawarman Samarinda. Demikian saran-saran terhadap pemanfaatan, diseminasi, maupun pengembangan produk lebih lanjut terhadap pengembangan pengembangan media pembelajaran bulutangkis dalam bentuk multimedia interaktif.

\section{DAFTAR RUJUKAN}

Akbar, S., \& Sriwiyana, H. (2010). Pengembangan Kurikulum dan Pembelajaran Ilmu Pengetahuan Sosial. Yogyakarta: Cipta Media.

Abdillah, F. T. (2010). Profesionalisme Guru Pendidikan Jasmani dan Kesehatan di Era Perkembangan Teknologi. Prosiding Seminar Nasional Profesionalisme Tenaga Profesi PJOK, 267-275

Baharudin. (2012). Pengaruh Penerapan Strategi Problem Based Learning Vs Strategi Ekspositori Berbantuan Multimedia Interaktif dan Gaya Belajar terhadap Hasil Belajar Fiqih dan Retensi Belajar Mahasiswa. Disertasi tidak diterbitkan. Universitas Negeri Malang, Malang.

Barnard, L., Lan, W. Y., To, Y. M., Paton, V. O., \& Lai, S. L. (2009). Measuring Self-Regulation in Online and Blended Learning Environments. Internet and Higher Education, 12(1), 1-6. https://doi.org/10.1016/j.iheduc.2008.10.005

Cairncross, S., \& Mannion, M. (2001). Interactive Multimedia and Learning: Realizing the benefits. Innovations in Education and Teaching International, 38(2), 156-164. https://doi.org/10.1080/14703290110035428.

Dwiyogo, W. D. (2008). Aplikasi Teknologi Pembelajaran. Malang: Fakultas Ilmu Pendidikan Universitas Negeri Malang.

Klentien, U., \& Wannasawade, W. (2016). Development of Blended Learning Model with Virtual Science Laboratory for Secondary Students. Procedia - Social and Behavioral Sciences, 217(2), 706-711. https://doi.org/10.1016/j.sbspro.2016. 02.126.

Lee, W. Owens. (2004). Multimedia-Based Intructional Design. San Fransisco: John Wiley \& Son Inc.

Munadi, Y. (2010). Media Pembelajaran. Jakarta: Gaung Persada Press.

Nazarenko, A. L. (2014). Information Technologies in Education: Blended Learning (an Attempt of a Research Approach). Procedia - Social and Behavioral Sciences, 154(10), 53-56. https://doi.org/10.1016/j.sbspro.2014.10.111

Pintrich, P. R., \& Groot, E. V. De. (1990). Motivational and Self Regulated Learning Components of Classroom Academic. Journal of Educational Psychology, 82(1), 33-40. 
Riyana, C. (2010). Peningakatan Kompetensi Pedagogis Guru melalui Penerapan Model Education Centre of Teacher Interactive Virtual (Educative). @ rtikulasi: Jurnal Kajian Bahasa dan Sastra Indonesia, 11(1), 40-48.

Stepp, J. G. (2002). Student Perceptions on Language Learning in a Technological Environment: Implications for The New Millennium. Language Learning and Technology, 6(1), 165-180.

Sugiyono. (2011). Metode Penelitian Kuantitatif Kualitatif dan R\&D. Bandung: Alfabeta.

Tasleden, U., \& Koseoglu, F. (2008). Learner-Friendly Textbooks: Chemistry Texts Based on a Contructivist View of Learning. Asia Pasific Education Review, 9(2), 136-147.

Wibowo, B, W. (2013). Media Pembelajaran Teknik Dasar Bulutangkis Berbasis Multimedia Interaktif (Studi kasus di Fakultas Ilmu Keolahragaan, Universitas Negeri Yogyakarta). Jurnal Sekolah Tinggi Informatika dan Komputer Amikom Yogyakarta.

Zitting, E., \& Krause, A. O. (2005). Blended Learning in Chemical Processes Education. Helsinki University of Technology: Laboratory of Industrial Chemistry, Departement of Chemical Technology. 